\title{
Stepping behavior and muscle activity of dairy cattle standing on concrete or rubber flooring for 1 or 3 hours
}

\author{
Karin E. Schütz, ${ }^{* 1}$ Eranda Rajapaksha,† Erin M. Mintline, $\ddagger$ Neil R. Cox, ${ }^{*}$ and Cassandra B. Tuckerł \\ ${ }^{*}$ AgResearch Ltd., Ruakura Research Centre, 10 Bisley Road, Hamilton 3214, New Zealand \\ †Department of Veterinary Clinical Science, Faculty of Veterinary Medicine and Animal Science, University of Peradeniya, 20400, Sri Lanka \\ ¥Center for Animal Welfare, Department of Animal Science, University of California, 1 Shields Avenue, Davis 95616
}

\begin{abstract}
The type of flooring in dairy cattle systems influences cows' health and welfare. Although concrete is common, the use of more compressible flooring, such as rubber, is increasing. Cows prefer to stand and walk on rubber surfaces than on concrete; however, it is largely unknown how walking and standing for longer periods of time influence muscle activity and fatigue. Therefore, we used measures of behavior and muscle activity to investigate the potential benefits of providing a rubber flooring surface to dairy cattle. Sixteen lactating Holstein cows were forced to stand on either concrete or rubber flooring for 1 or $3 \mathrm{~h}$ in a $2 \times 2$ crossover design. Surface electromyograms (SEMG) and skin surface temperature were used to evaluate muscle activity, fatigue, and movement of muscle activity between the hind legs. Activity of 2 muscles, the bicep femoris and middle gluteal, was assessed during both static contractions, when cows transferred weight to each hind leg, before and after 1 and $3 \mathrm{~h}$ of standing, and dynamic contractions, associated with steps and with shifts in weight without steps. In addition, we evaluated stepping rate, time between each step, feeding behavior, skin surface temperature, and latency to lie down after standing. Standing duration influenced both the behavior and muscle activity of cows. Stepping rate increased with standing time for cows on both flooring types. Static muscle activity parameters of the bicep femoris muscle were higher after $3 \mathrm{~h}$ of standing for cows standing on both flooring types (2.3 and $3.6 \%$ increases in median amplitude and median power frequency, respectively) compared with the change after $1 \mathrm{~h}$ and compared with baseline values before the standing treatment. Flooring type influenced the behavior and muscle activity of the cows, particularly during the first hour of exposure;
\end{abstract}

Received February 18, 2018.

Accepted June 18, 2018.

${ }^{1}$ Corresponding author: karin.schutz@agresearch.co.nz cows standing on rubber had a higher stepping rate, shorter interval between steps, and higher number of SEMG shifts (muscle activity shifts with or without visible steps) than cows on concrete. There was no difference in skin surface temperature, feeding behavior, or latency to lie down between the treatments. The results show that standing on a rubber flooring caused a different initial behavioral response compared with standing on concrete; however, possible reasons for these changes are unclear. Standing for $3 \mathrm{~h}$ resulted in an increase in stepping rate and in some muscle activity parameters; however, the results regarding muscle fatigue in relation to flooring type are inconclusive.

Key words: behavior, electromyogram, flooring, muscle fatigue

\section{INTRODUCTION}

The type of flooring in housing conditions influences the health and welfare of dairy cattle. Cows in freestall systems spend between 46 and $60 \%$ of their daily time standing (Ito et al., 2009), most commonly on concrete surfaces. Cows can also be exposed to long periods of standing on hard surfaces in other management systems and situations, such as while waiting for milking, veterinary treatment, or breeding, or when confined to concrete yards during periods of wet weather to protect pasture integrity in grazing-based systems. For example, dairy herds in Australia with more than 300 cows were more likely to have cows standing in the yard for more than $2 \mathrm{~h}$ before being milked compared with smaller herd sizes (Beggs et al., 2015).

Concrete surfaces have several characteristics, such as hardness and low coefficient of friction (Hinterhofer et al., 2005; Telezhenko and Bergsten, 2005; van der Tol et al., 2005), that have negative effects on the health and welfare of cows. Indeed, concrete surfaces are associated with increased incidence of lameness and hoof problems in dairy cattle (Somers et al., 2003; Vanegas et al., 2006; Ouweltjes et al., 2009). It is becoming more common to use rubber flooring, which is softer and provides more traction than concrete, to improve housing 
conditions. Cattle prefer and spend more time standing (Tucker et al., 2006; Telezhenko et al., 2007; Haufe et al., 2009) and lying (Schütz and Cox, 2014) on rubber surfaces rather than concrete. Rubber flooring also has the potential to improve locomotion, particularly in lame cows (Flower et al., 2007).

Whereas rubber flooring is used to improve housing conditions, cows are still routinely forced to stand on concrete as a part of different management procedures, and the literature regarding the effects in these situations are mixed. The comfort of cows during periods of standing has been evaluated using different behavioral measures. Suggested indicators of problems include shifting of weight between legs and stepping frequency, as lame cows perform more of these behaviors than healthy cows (Pastell and Kujala, 2007; Chapinal and Tucker, 2012). Both weight shifting and number of steps taken increase with time when cows stand on concrete and rubber (Cooper et al., 2007; Krebs et al., 2011) and this increase is apparent within $1 \mathrm{~h}$ of standing (Chapinal et al., 2011; Rajapaksha and Tucker, 2015). Interestingly, although cattle seem to have a clear preference for rubber surfaces, studies assessing stepping rate and weight shifting during forced standing on rubber or concrete for $1 \mathrm{~h}$ (Chapinal and Tucker, 2012) or $4 \mathrm{~h}$ (Krebs et al., 2011) have not found any differences between the 2 flooring types. In the study by Krebs et al. (2011), stepping frequency increased with time when cows were forced to stand on either concrete or rubber for $4 \mathrm{~h}$ in front of the feed bunk, but there was no difference between treatments. In the abovementioned studies, weight shifting was measured using load cells and stepping rate by visual observations, and the authors suggested that an alternative methodology to measure more subtle shifts in weights may be needed to assess effects of rubber flooring.

Surface electromyography (SEMG) has been used to measure muscle activity and in some cases, muscle fatigue, in horses (Robert et al., 2000; Colborne et al., 2001; Licka et al., 2009), dogs (Bockstahler et al., 2009), and recently in dairy cattle during forced standing on different types of flooring (Rajapaksha and Tucker, 2014, 2015; Rajapaksha et al., 2015). Surface electromyography provides a more detailed analysis of how animals respond to different surface types compared with behavior alone, and combined measures of SEMG and behavior have been used to assess dairy cattle when forced to stand on either concrete or rubber for $1 \mathrm{~h}$ (Rajapaksha et al., 2015). The rubber flooring had little effect on the visible stepping behavior; however, the frequency of muscle activity movements between the hind legs was greater when cows stood on concrete for $1 \mathrm{~h}$ compared with rubber (Rajapak- sha et al., 2015). Those authors found no indication of muscle fatigue in cows standing for $1 \mathrm{~h}$ on either surface (as measured by changes in median power frequency, MPF, and median amplitude, MA), but the duration of the standing exposure in that study may have been too short to detect any effects on muscle fatigue. Because it is not uncommon for dairy cows to be standing on hard surfaces for more than $1 \mathrm{~h}$, the current study aimed to determine the behavioral and physiological responses, including muscle activity and fatigue, of dairy cattle to forced standing for 1 or $3 \mathrm{~h}$ on either a 25-mm-thick rubber surface or concrete. We predicted that cows on both flooring types would show an increase in stepping behavior and skin surface temperature with increased standing duration. We also predicted that cows on concrete would show more signs of muscle activity overall and signs of muscle fatigue after $3 \mathrm{~h}$ of standing compared with cows on rubber.

\section{MATERIALS AND METHODS}

This experiment was conducted at the University of California-Davis dairy facility during the spring of 2013. All procedures and research protocols were reviewed and approved by the University of California, Davis Institutional Animal Care and Use Committee.

\section{Animals and Housing}

Sixteen lactating Holstein cows (BW $691 \pm 69 \mathrm{~kg}$, DIM $189 \pm 53$, weekly milking average $38.1 \pm 3.8 \mathrm{~kg}$; mean $\pm \mathrm{SD}$ ) were tested in groups of 4 . Cows were clinically healthy and had an average gait score (Flower and Weary, 2006) of $1.1 \pm 0.17$ pre-testing and $1.0 \pm$ 0.14 post-testing (mean $\pm \mathrm{SD}$ ). Twelve cows were in first lactation, and 4 were in second lactation. Cows were housed in a grooved-concrete floored pen with 24 covered head-to-head freestalls $(1.2 \times 2.4 \mathrm{~m} ; 1$ cow per freestall) that were deep-bedded with sand and had a neck rail located $106 \pm 2 \mathrm{~cm}$ above the surface. Cows were milked twice daily at 0500 and 1600 h. Feeding occurred 3 times per day, at 0400, 1100, and $1600 \mathrm{~h}$. Cows were fed a TMR of $37 \%$ alfalfa hay, $36 \%$ grain mix, $10 \%$ whole cotton seed, $12 \%$ almond hulls, $2 \%$ soybean meal, and 3\% mineral mix on a DM basis. Water was available ad libitum in their home pen.

\section{Experimental Procedures}

Before the start of data recording, the cows were habituated to the standing areas utilized in the study over a 2 -d period. At the time of testing, cows were moved to a covered preparation and test area located 
$20 \mathrm{~m}$ away from the home pen. The test area contained 2 separate standing areas ("stalls"), each $2.4 \mathrm{~m} \times 1.2$ $\mathrm{m}$ and constructed of steel panels (Powder River Inc., Provo, UT). One stall had smooth, poured, gray concrete surface under all legs (CON) and another surface consisted of a new black rubber mat (RUB, 25-mmthick interlocking mat, $1.22 \mathrm{~m}$ wide, $2.44 \mathrm{~m}$ long, Agrimat Legend; Numat Ltd., Oamaru, New Zealand) placed over concrete under all legs. The concrete treatment was created by closely aligning 8 square $(30 \mathrm{~cm} \times$ $30 \mathrm{~cm}$ ) slabs that were $7.6 \mathrm{~cm}$ thick and placed on level ground. The height of the floor from the ground was equal for both CON and RUB treatments.

In a $2 \times 2$ crossover design, each cow was tested on each floor type for $1 \mathrm{~h} / \mathrm{d}$ and $3 \mathrm{~h} / \mathrm{d}$, for a total of $4 \mathrm{~d}$ of testing/cow. The 3 -h test periods were divided into 4 intervals for the first, second, and third hours of testing; the first $30 \mathrm{~min}$ of standing (interval 1), 30 to 60 min of standing (interval 2), 90 to 120 min of standing (interval 3), and 150 to $180 \mathrm{~min}$ of standing (interval 4). The 1-h test periods were divided into 2 intervals (intervals 1 and 2). Two animals were tested each day between 0800 and $1400 \mathrm{~h}$ and each animal had a rest day between each treatment. Animals were tested in the same order on each day. The order of exposure to treatments was balanced across cows to receive a combination of flooring and time in a unique order. Because of milking time constraints, one 1-h treatment and one 3-h treatment were tested on each day; 2 cows receiving the 3 -h treatment could not be tested on the same day.

The location of the floors in the testing area relative to one another was changed over the course of the study; floor location was switched between every group of cows. During testing, 2 horizontal metal bars were placed on the back end of the stall to confine the cows. The cows could move their heads and look sideways and take a few steps forward or backward, but all legs remained on the intended treatment. Water was available ad libitum in the treatment stalls (a water bucket was refilled immediately if emptied during testing). A TMR was also provided during testing; a feed bucket was mounted in the stall and filled at the beginning of every hour to a line that corresponded to approximately $3 \mathrm{~kg}$ of feed.

\section{Behavior Measures}

Stepping Behavior. Stepping behavior during all 4 intervals was recorded using live observations by trained observers using data input software Etholog version 2.2 (Ottoni, 2000). The total number of steps/ minute, time between each consecutive step, and the coefficient of variation $(\mathrm{CV})$ of the time between steps were calculated for each treatment. A step was defined as lifting any part of the hoof off the ground and was recorded separately for all 4 legs. Observers had high interobserver reliability $(\mathrm{r}=0.998)$, measured by correlation with observations of an experienced person (E. Mintline) as a gold standard. Video recordings were used as back-up in the case of live observation malfunction. The video recordings were collected with 4 CVC627B color CCTV video cameras (Speco Technologies, Amityville, NY) connected to a digital video recorder with a GV-1120/1240/1480 combo card (USA Vision Systems Inc., Irvine, CA) and IPD-NVR16 digital surveillance software (ClearVision Inc., Wheeling, IL).

Feeding Behavior. Feeding behavior was measured during all 4 intervals using live instantaneous 30 -s scan sampling. Feeding was defined as muzzle (nostrils and chin) in feed bucket or muzzle out of feed bucket and cow chewing with (fresh) feed in the mouth. Feeding was differentiated from ruminating, which was not recorded. Inter-observer reliability, measured as percentage agreement between observers, was $98 \%$.

Lying Behavior. Lying behavior was recorded with Onset Pendant G data loggers (64k, Onset Computer Corp., Bourne, MA). The loggers were placed in a silicone block, wrapped with VetWrap cohesive bandage (3M Products, St. Paul, MN), and placed directly on the medial plane of the leg. Loggers were set to record the $\mathrm{y}$-axis at 30-s intervals, and lying and standing data points were summarized using a SAS code (UBC Animal Welfare Program, 2013). Isolated readings (representing both 30 and $60 \mathrm{~s}$ ) of lying and standing were deleted, using the algorithm and validation described by Ledgerwood et al. (2010). Latency to lie down after each testing session was calculated using the data generated from loggers.

\section{SEMG Evaluations}

Before each testing session, cows were prepared for SEMG recordings according to the procedure described by Rajapaksha and Tucker (2014). Cows were then moved to treatment flooring and confined. Eight selfadhesive bipolar surface electrodes with 4 ground electrodes (3M Red Dot Repositionable Electrodes, Ag/ $\mathrm{AgCl}$, St. Paul, MN) were attached on the skin over the middle gluteal muscle (an extensor of the hip joint and abductor of the leg that controls hip movements) and the biceps femoris muscle (extensor of the hip and stifle and flexor of the stifle) on both the right and left sides of the cow.

An electromyography telemetric system with a common mode rejection ratio of $110 \mathrm{~dB}$ (Megawin Biomoni- 
tor ME 6000, Mega Electronics Ltd., Kuopio, Finland), was used to record SEMG readings during both static and dynamic muscle contractions. All SEMG signals were recorded at $1,000 \mathrm{~Hz}$ and pre-amplified (input impedance $=10 \mathrm{G} \Omega$, gain 305). Signals were filtered with a low-pass Butterworth filter (bandwidth 8-500 $\mathrm{Hz}$ ). Data recording and preparation for analysis was done with Megawin version 2.3 (Mega Electronics Ltd.). Raw signals were fast Fourier transformed for frequency domain analysis, and SEMG power spectra were created and used to acquire MPF values for all muscle contractions. The MA and total muscle activity were calculated for statistical analysis by using root mean square (RMS) average of signals.

Static Contractions. Static reference volumetric contractions were measured during standing on the treatment flooring to measure fatigue in tested muscles. Two measures were taken, one at the start $(0 \mathrm{~min})$ and one after each standing session. To generate these contractions, cows were forced to transfer their weight to each hind leg, in turn, by placing a wooden board with fixed carriage bolts covered by a thin rubber mat under the other hind leg (Rajapaksha and Tucker, 2014). Readings were recorded for both muscles for $30 \mathrm{~s}$, and then repeated for the other hind leg. Differences of MPF and MA values from static contractions between start and the end of testing were used to evaluate muscle fatigue (defined as decreased MPF and increased MA; Luttmann et al., 2000).

Dynamic Contractions. Continuous numbers of SEMG shifts (muscle activity shifts with or without visible steps) were recorded during all 4 intervals. Total muscle activity ( $\mu \mathrm{V}$ associated with all steps and standing activity) generated during SEMG recording was calculated for all 4 intervals. In addition, SEMG values from a 15-min period within each interval were used to evaluate MPF and MA change over time to evaluate fatigue during dynamic contractions. To do this, the first 3 right-left consecutive stepping events (with 1 step per leg) in each 15-min period were used to generate the MPF and MA values.

\section{Surface Temperature}

Surface temperature was recorded on both sides of the hind legs using data loggers (Thermochron iButton DS1921H, accuracy: $\pm 1.0^{\circ} \mathrm{C}$, resolution: $\pm 0.125^{\circ} \mathrm{C}$; Embedded Data Systems, Lawrenceburg, KY) recording at 1-min intervals. These loggers were attached next to the EMG electrodes using surgical tape (3M Micropore, St. Paul, MN). Surface temperature was averaged in the 4 intervals for analysis. The loggers were not exposed to sunlight during recording as the test area was covered.

\section{Statistical Analysis}

All statistical analyses were carried out using the cow as the experimental unit $(\mathrm{n}=16)$, combining the data for the 2 hind legs. Number of SEMG shifts, time spent feeding, stepping behavior (including time between steps), and surface temperature needed log-transformation and were then analyzed using a repeated-measures ANOVA with uniform correlation covariance structure. Each interval was analyzed separately. The ANOVA included factors for floor type, standing time, order of testing, muscle, and their interactions. The order factor and its interactions were not significant and were excluded from the subsequent analyses. Latency to lie down, static SEMG, dynamic SEMG associated with steps, $\mathrm{CV}$ of the time between steps, and total SEMG $(\mu \mathrm{V} /$ min) were analyzed using the same model but without data transformation. We also compared intervals 1 and 2 for animals in the 1-h treatment with intervals 3 and 4 for animals in the 3 -h treatment (SEMG shifts, feeding, number of steps, time and CV between steps, and total SEMG) as well as the difference between interval 1 and 2 for the animals in the 1-h treatment, and the difference between interval 1 , interval 3 , and interval 4 for animals in the 3 -h treatment (SEMG associated with steps). The treatment degrees of freedom was 1 for each treatment, and the error degrees of freedom was 45. All statistical analyses were conducted using the statistical package GenStat, version 13.2 (VSN International, Hemel Hempstead, UK).

\section{RESULTS}

\section{Feeding Behavior}

Cows spent a similar amount of time feeding irrespective of floor type and standing time $(P \geq 0.205)$. Cows spent, on average, 18.1 and $17.0 \%$ of time feeding for CON and RUB, respectively (range: 15.1 to $20.9 \%$, and 11.6 to $24 \%$ for the different intervals for CON and RUB, respectively). There was no interaction between floor type and standing time for any of the intervals $(P$ $\geq 0.224)$.

\section{Latency to Lie Down}

We observed no effect of floor type $(P=0.849)$, standing time $(P=0.526)$, or their interaction $(P=$ $0.411)$ on latency to lie down after the treatments. The latency to lie down was on average, for CON-1 h: 75 min, CON-3 h: 65 min, RUB-1 h: 68 min, and RUB-3 h: $69 \mathrm{~min}$ (SEM: $7 \mathrm{~min}$ ). The latency to lie down ranged from $20 \mathrm{~min}$ to $2.43 \mathrm{~h}$ (SD: $30 \mathrm{~min}$ ). 
Table 1. Change in median amplitude $\left(\mathrm{MA} ;\right.$ mean $\left.\%, \mathrm{SED}^{1}\right)$ and median power frequency (MPF; mean $\%$, SED) of dairy cattle $(\mathrm{n}=16)$ before and after standing on floors that varied in type and standing time

\begin{tabular}{|c|c|c|c|c|c|c|c|c|}
\hline Variable and muscle & \multicolumn{2}{|c|}{ Floor type $^{2}$} & $P$-value & \multicolumn{2}{|c|}{ Standing time ${ }^{3}$} & $P$-value & SED & $\begin{array}{c}\text { Interaction }^{4} \\
P \text {-value }\end{array}$ \\
\hline Biceps femoris & 1.0 & -0.6 & 0.361 & -1.9 & 2.3 & 0.033 & 1.9 & 0.501 \\
\hline Middle gluteal & -0.4 & 0.8 & 0.593 & 1.8 & -1.4 & 0.186 & 2.3 & 0.040 \\
\hline Both muscles & 0.3 & 0.1 & 0.897 & -0.1 & 0.4 & 0.791 & 1.7 & 0.078 \\
\hline \multicolumn{9}{|l|}{ MPF } \\
\hline Both muscles & 3.8 & 2.5 & 0.492 & 2.0 & 4.3 & 0.221 & 1.8 & 0.132 \\
\hline
\end{tabular}

${ }^{1}$ Standard error of the difference.

${ }^{2} \mathrm{CON}=$ concrete, $\mathrm{RUB}=$ rubber.

${ }^{3} 1$ versus $3 \mathrm{~h}$ of continuous standing on each flooring.

${ }^{4}$ Interaction between floor type and standing time.

\section{Static SEMG Recordings}

Static SEMG recordings before and after standing time are presented in Table 1. Floor type did not influence muscle activity (MA and MPF) for either muscle $(P \geq 0.229)$ but standing time did; the increase in muscle activity (from baseline) of the bicep femoris muscle was higher $\left(P_{\mathrm{MA}}=0.033, P_{\mathrm{MPF}}<0.001\right.$; Table 1) after $3 \mathrm{~h}$ of standing (2.3 and $3.6 \%$ increase in MA and MPF, respectively) compared with the change after $1 \mathrm{~h}$ of standing (1.9 and $2.8 \%$ decrease in MA and MPF, respectively). We detected an interaction between flooring type and standing time for the middle gluteal muscle (Table 1); MA and MPF decreased for cows standing on concrete during the periods of standing, whereas both variables increased for cows on rubber flooring (Figure 1).

\section{Stepping Behavior and Associated SEMG Recordings}

The number of SEMG shifts, actual steps (recorded live using video observations), and time and CV between steps are presented in Table 2. On average, cows standing on rubber stepped more $(0.75$ steps $/$ min more, $P=0.003$; Figure 2) and had shorter time between steps (5 s shorter) during interval 1 (first $30 \mathrm{~min}$ of testing, $P=0.001$ ) compared with cows on concrete. Similarly, cows standing on rubber had 2.4 more SEMG shifts (per min) during interval 2 (second 30 min of the first hour of testing, $P=0.047)$ and shorter time $(1 \mathrm{~s}$ less) between steps than cows on concrete $(P=0.042)$. The number of actual steps taken increased and, consequently, the time between steps decreased for cows on both flooring types during the 3 -h standing time $(P \leq$ 0.002; Figure 2). However, SEMG shifts were relatively constant over $3 \mathrm{~h}$ of standing. There was no interaction between floor type and standing time for any variable $(P \geq 0.056$; Table 2).

Surface electromyography recordings of muscle activity associated with stepping behavior (dynamic contractions) are presented in Table 3. Flooring type influenced how MA for the biceps femoris muscle changed throughout the periods of standing. Median amplitude associated with stepping was lower than baseline (negative values) for cows standing on $\mathrm{CON}$ and higher than baseline (positive values) for cows on RUB; these changes were evident after $1 \mathrm{~h}$ of standing and exacerbated throughout the 3-h standing treatment. A similar pattern was seen in the middle gluteal muscle after $3 \mathrm{~h}$ of standing. The MPF associated with stepping behavior for either muscle or the muscles combined was not influenced by floor type or standing time $(P \geq 0.114)$.

\section{Total Muscle Activity}

Total muscle activity $(\mu \mathrm{V} / \mathrm{min})$ is presented in Figure 3. Neither floor type, standing time, nor their interaction influenced total muscle activity $(P \geq 0.110)$.

\section{Skin Temperature}

The mean increase in surface temperature compared with the average of the first $30 \mathrm{~min}$ of recording for both muscles was for $\mathrm{CON}-1 \mathrm{~h}: 0.05^{\circ} \mathrm{C}, \mathrm{CON}-3 \mathrm{~h}$ : $0.89^{\circ} \mathrm{C}$, RUB- $1 \mathrm{~h}: 0.03^{\circ} \mathrm{C}$, and for RUB- $3 \mathrm{~h}: 0.81^{\circ} \mathrm{C}$ (SEM: $0.11^{\circ} \mathrm{C}$ ). Neither floor type, standing time, nor their interaction influenced surface temperature $(P \geq$ 0.095); however, all cows in the 3 -h treatments had higher surface temperature at the end of the standing duration, irrespective of flooring type. 

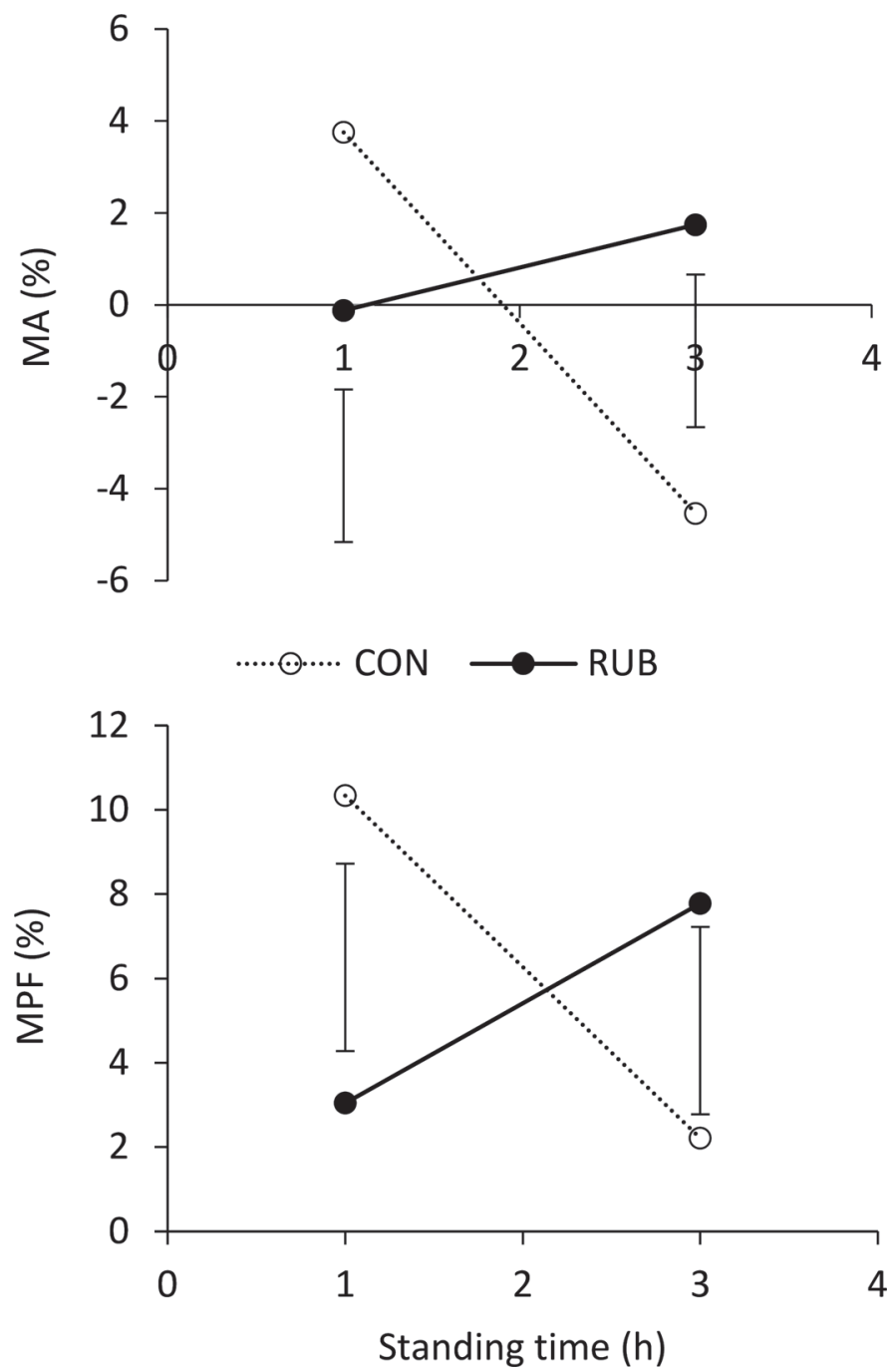

Figure 1. Difference (\%) in median amplitude (MA) and median power frequency (MPF) of the middle gluteal muscle of dairy cattle (n $=16$ ) when forced to stand on either concrete $(\mathrm{CON})$ or rubber (RUB) for 1 and $3 \mathrm{~h}$. Values are the mean difference between after and before each standing time and the standard error of the difference. For the interaction between flooring type and standing duration: $P=0.040$ for $\mathrm{MA}, P=0.056$ for $\mathrm{MPF}$.

\section{DISCUSSION}

Cows showed an initial response to the rubber surface by increasing the rate of combined weight shifting and steps. Standing for $3 \mathrm{~h}$ resulted in an increase in stepping rate and in some muscle activity parameters; however, the results regarding fatigue in relation to flooring type were inconclusive.

The increase in stepping rate with standing time in the present study agreed with other studies investigating similar flooring types and standing times (Krebs et al., 2011; Rajapaksha and Tucker, 2015) but were greater than values reported for dairy cattle standing on concrete for 2 or $4 \mathrm{~h}$ (Cooper et al., 2007). Differences in stepping rate may be due in part to methodological differences between studies (e.g., different behavioral definitions and testing cows individually or in pairs); however, increased stepping has been suggested as a measure of discomfort because lame cows step more than nonlame cows and animals standing on an uncomfortable surface with one hoof step more than those on a more comfortable surface (Neveux et al., 2006; Chapinal and Tucker, 2012; Rajapaksha and Tucker, 2015). Recent evidence suggests that the interpretation of increased stepping with time is not straightforward, as increased stepping rate did not result in muscle fatigue or shorter latency to lie down after testing (Rajapaksha and Tucker, 2014). It is uncertain what this change in behavior means in terms of discomfort-previous studies have shown that dairy cattle prefer to stand and walk on rubber surfaces over concrete (Tucker et al., 2006; Telezhenko et al., 2007). In human studies, postural swaying has been suggested to reduce discomfort caused by, for example, physiological factors, such as low blood flow, muscular fatigue, and increased joint pressure (Freitas et al., 2005). Similarly, stepping in cows may indicate discomfort or steps could function as a means to avoid fatigue through increased blood circulation to the muscles. Therefore, steps may not be a reliable indicator of discomfort in cows.

During the first $30 \mathrm{~min}$ of standing, the cows on the rubber flooring had more steps per minute and shorter intervals between steps than cows on concrete. In addition, cows on the rubber flooring had more SEMG shifts and shorter interval between steps during interval 2 (30 to $60 \mathrm{~min}$ of standing). However, flooring treatments did not differ in number of steps per minute after $3 \mathrm{~h}$ of standing, which agrees with other studies where cows stood on concrete or rubber for 4 and $1 \mathrm{~h}$ (Krebs et al., 2011; Chapinal and Tucker, 2012; Rajapaksha et al., 2015). Because the effect of rubber on stepping behavior was evident during the first hour of testing only, we speculate that the increase in stepping behavior on rubber flooring is an attempt by animals to avoid the discomfort associated with standing, potentially to increase blood flow in the muscles. The lack of this response while standing on concrete could be due to cows finding this surface more uncomfortable to step on than rubber. However, as the stepping rate between cows on rubber and concrete was very similar after $3 \mathrm{~h}$ of standing, cows on both flooring types may adopt the same behavior over time to avoid muscle fatigue. The findings further suggest that the interpretation of increased stepping as a measure of discomfort is complex and warrants further research. We speculate that cows may 
Table 2. Surface electromyogram (SEMG) $\operatorname{shifts}^{1}$ (number of shifts per $30 \mathrm{~min}$ ), number of steps ${ }^{1}$ (per min), time between steps ${ }^{1}(\mathrm{~s})$, and $\mathrm{CV}$ of the time between steps of dairy cattle $(\mathrm{n}=16)$ during standing on floors that varied in type and standing time

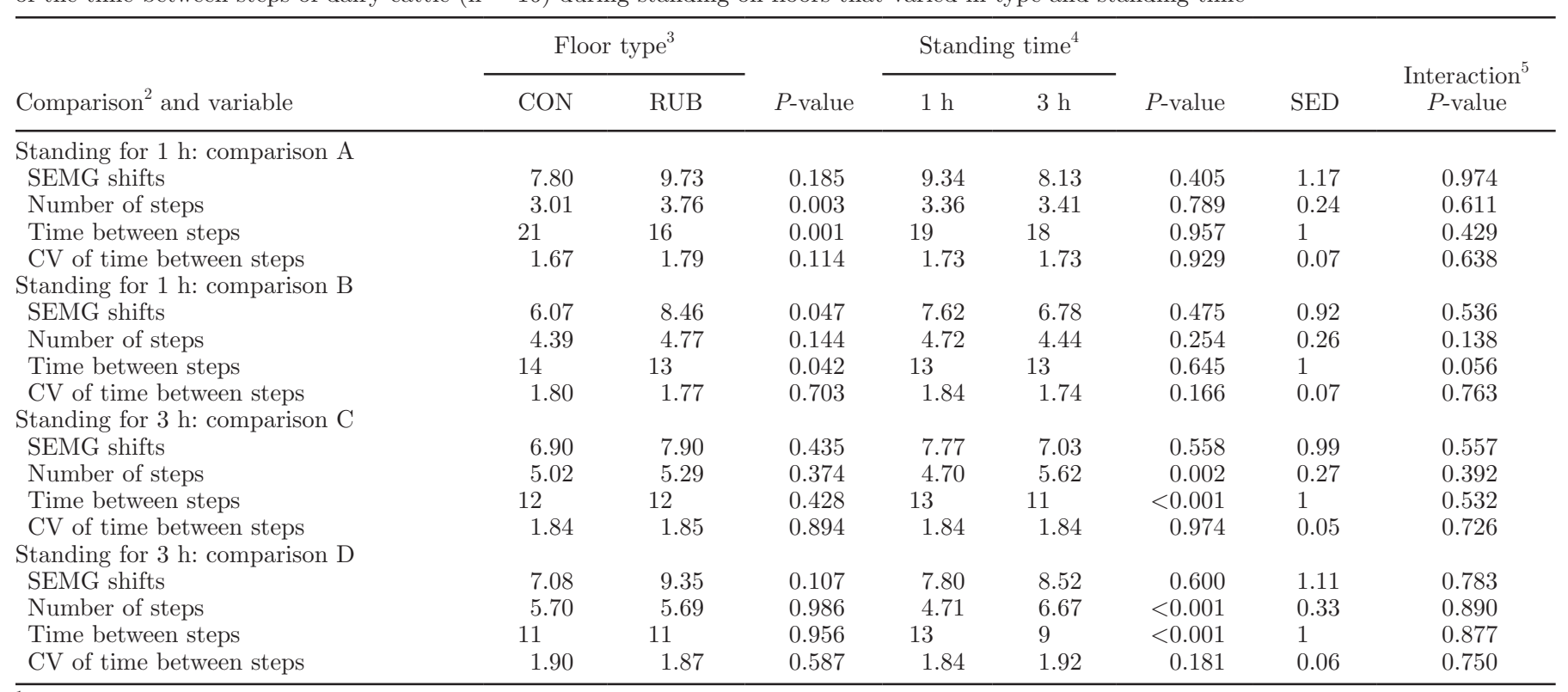

${ }^{1}$ Back-transformed means and standard error of the difference (SED).

${ }^{2}$ Comparisons were made at 4 time points: (A) interval 1 (first 30 min of standing), (B) interval 2 (30 to 60 min), (C) comparison of interval 2 and interval 3 (90 to $120 \mathrm{~min}$ ), and (D) comparison of interval 2 and interval 4 (150 to $180 \mathrm{~min}$ ).

${ }^{3} \mathrm{CON}=$ concrete, $\mathrm{RUB}=$ rubber.

${ }^{4} 1 \mathrm{~h}$ versus $3 \mathrm{~h}$ of continuous standing on each flooring.

${ }^{5}$ Interaction between floor type and standing time.

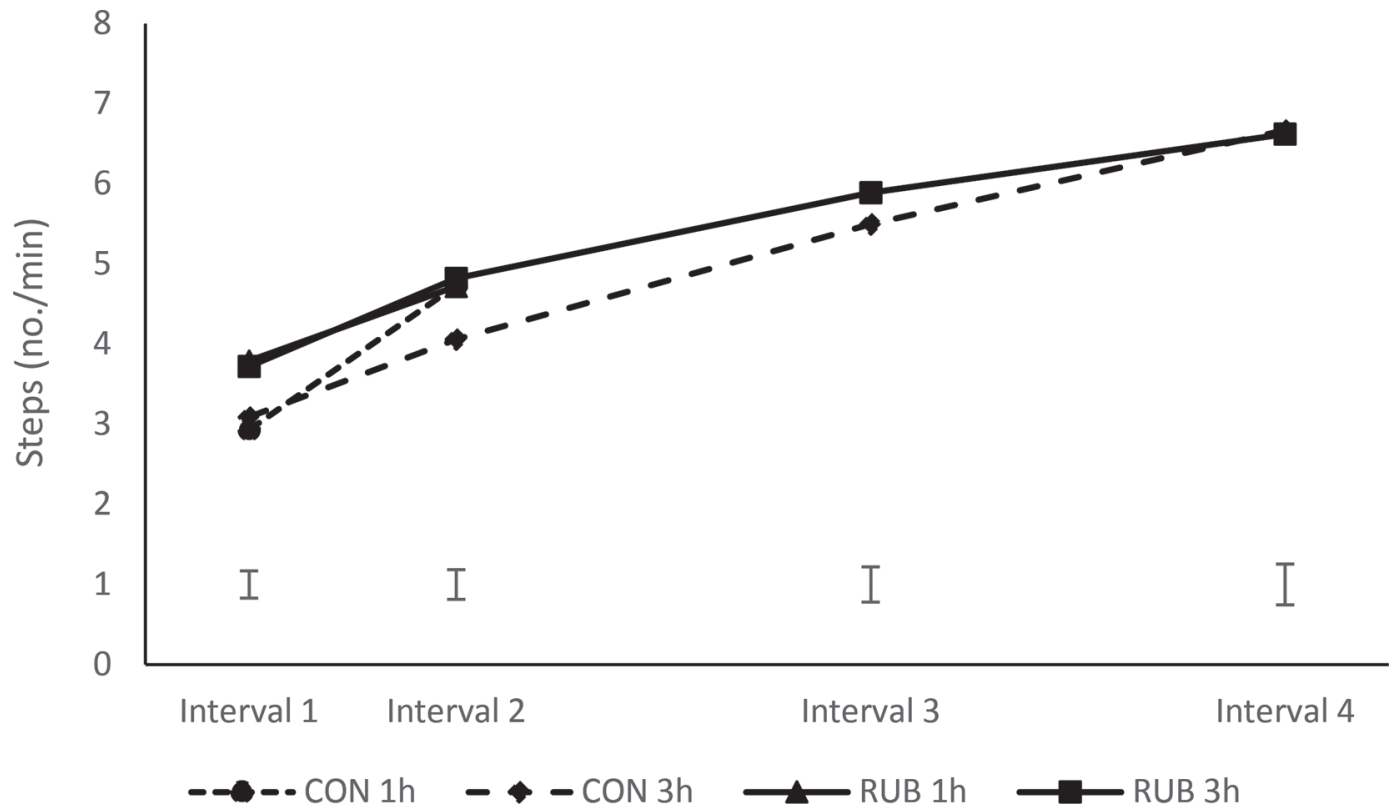

Figure 2. Mean number of steps per minutes (and standard error of the difference) by dairy cattle $(\mathrm{n}=16)$ standing on either concrete $(\mathrm{CON})$ or rubber (RUB) flooring for 1 and $3 \mathrm{~h}$ (interval 1 = first $30 \mathrm{~min}$ of standing; interval $2=30$ to 60 min; interval $3=90$ to 120 min; interval $4=150$ to $180 \mathrm{~min}$ ). The intervals are unequally spaced to reflect that intervals 1 and 2 were within the first hour of testing, whereas interval 3 was in the second hour, and interval 4 in the third hour of testing. 
Table 3. Change in median amplitude (MA; \% mean and $\mathrm{SED}^{1}$ ) and median power frequency (MPF; \% mean and SED) associated with stepping behavior in dairy cattle $(\mathrm{n}=16)$, during standing on floors that varied in type and standing time (1 vs. $3 \mathrm{~h}$ on each type)

\begin{tabular}{|c|c|c|c|c|}
\hline \multirow[b]{2}{*}{ Comparison $^{2}$ and variable } & \multicolumn{2}{|c|}{ Floor type $^{3}$} & \multirow[b]{2}{*}{$P$-value } & \multirow[b]{2}{*}{ SED } \\
\hline & $\mathrm{CON}$ & RUB & & \\
\hline \multicolumn{5}{|c|}{ Standing for $1 \mathrm{~h}$ : comparison A } \\
\hline \multicolumn{5}{|c|}{ MA } \\
\hline Biceps femoris & -0.50 & 1.44 & 0.027 & 0.85 \\
\hline Middle gluteal & -0.22 & 0.07 & 0.814 & 1.21 \\
\hline Both muscles & -0.36 & 0.75 & 0.233 & 0.92 \\
\hline \multicolumn{5}{|l|}{ MPF } \\
\hline Biceps femoris & 2.50 & -3.30 & 0.161 & 4.06 \\
\hline Middle gluteal & 1.70 & -1.20 & 0.401 & 3.49 \\
\hline Both muscles & 2.10 & -2.30 & 0.170 & 3.13 \\
\hline \multicolumn{5}{|c|}{ Standing for $3 \mathrm{~h}$ : comparison B } \\
\hline \multicolumn{5}{|c|}{ MA } \\
\hline Biceps femoris & -1.95 & 0.49 & 0.016 & 0.97 \\
\hline Middle gluteal & -0.69 & 0.28 & 0.424 & 1.20 \\
\hline Both muscles & -1.32 & 0.39 & 0.062 & 0.89 \\
\hline \multicolumn{5}{|l|}{ MPF } \\
\hline Biceps femoris & 6.70 & 1.60 & 0.159 & 3.56 \\
\hline Middle gluteal & 6.20 & 4.20 & 0.610 & 3.87 \\
\hline Both muscles & 6.40 & 2.90 & 0.294 & 3.33 \\
\hline \multicolumn{5}{|c|}{ Standing for $3 \mathrm{~h}$ : comparison $\mathrm{C}$} \\
\hline \multicolumn{5}{|c|}{ MA } \\
\hline Biceps femoris & -2.94 & 1.26 & $<0.001$ & 1.00 \\
\hline Middle gluteal & -2.38 & 1.03 & 0.007 & 1.21 \\
\hline Both muscles & -2.66 & 1.15 & $<0.001$ & 0.90 \\
\hline \multicolumn{5}{|l|}{ MPF } \\
\hline Biceps femoris & 4.30 & -0.30 & 0.175 & 3.36 \\
\hline Middle gluteal & 7.60 & 3.10 & 0.216 & 3.60 \\
\hline Both muscles & 5.90 & 1.40 & 0.144 & 3.08 \\
\hline
\end{tabular}

${ }^{1}$ Standard error of the difference.

${ }^{2}$ Comparisons with interval 1 (first 30 min of standing) were made at 3 time points: (A) interval 2 (30 to 60 $\mathrm{min}$ ), (B) interval 3 (90 to $120 \mathrm{~min}$ ), and (C) interval 4 (150 to $180 \mathrm{~min}$ ).

${ }^{3} \mathrm{CON}=$ concrete, $\mathrm{RUB}=$ rubber.

step more and shift more weight between the hind legs when standing on a more comfortable surface to avoid muscle fatigue and discomfort, a behavior that may be more subtle than the hoof lifting associated with an acute pain in the hoof. However, this is in contrast to the findings of Chapinal et al. (2011), where cows standing on rubber and concrete for $1 \mathrm{~h}$ had the same stepping rate. The different rubber mats used in the 2 studies may have contributed to the different results. For example, 2 revulcanized rubber mats (each $1.9 \mathrm{~cm}$ thick) were used in Chapinal et al. (2011), whereas a different brand of rubber mat was used in the present study. It is likely that the 2 rubber surfaces had different levels of compressibility or traction that may have influenced animal responses. In addition, the cows in the different studies may have had varying degrees of previous exposure to rubber surfaces.

The static SEMG suggested increased MA and MPF of the bicep femoris muscle for cows on both flooring types after $3 \mathrm{~h}$, which is an indication of increased muscle activity occurring due to recruitment of more motor units (Hägg et al., 2000). However, we also detected an interaction between flooring type and standing time for the middle gluteal muscle; these results suggest that cows standing on concrete may have experienced muscle force decrease (less muscle activity) in the middle gluteal muscle (indicated by a decrease in MA and MPF compared with the baseline), whereas cows standing on rubber activated more muscle units (indicated by an increase of both variables).

There was no increase in total muscle activity after 3 $\mathrm{h}$ of standing (measured as the area difference), which agrees with Rajapaksha et al. (2015), where cows stood on concrete or rubber for $1 \mathrm{~h}$. This lack of increase in total muscle activity could be explained by the 2 muscles cancelling each other out; that is, over time, the activity of the bicep femoris increased for cows on both flooring types and the activity of the middle gluteal decreased for cows on concrete. In addition, cows from all treatments had similar latency to lie down after the treatment (69 min), which is similar to cows that stood for $1 \mathrm{~h}$ on concrete or rubber matting (61 min, 


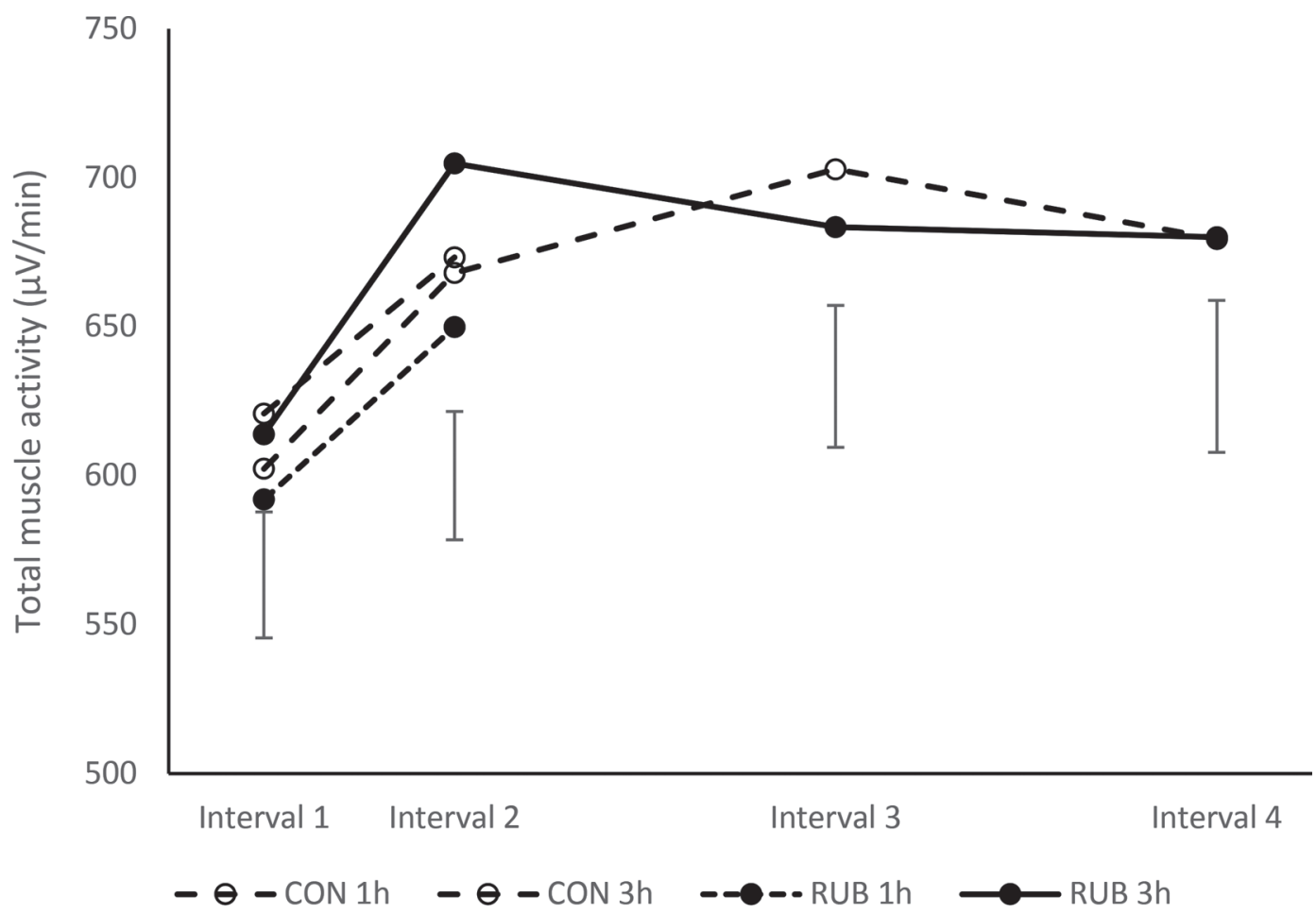

Figure 3. Total muscle activity $(\mu \mathrm{V} / \mathrm{min}$; mean, standard error of the difference; gluteal and biceps femoris muscles combined) in dairy cattle $(\mathrm{n}=16)$ during standing on either concrete $(\mathrm{CON})$ or rubber (RUB) flooring for 1 or $3 \mathrm{~h}$ (interval $1=$ first 30 min of standing; interval $2=30$ to $60 \mathrm{~min}$; interval $3=90$ to $120 \mathrm{~min}$; interval $4=150$ to $180 \mathrm{~min}$ ). The intervals are unequally spaced to reflect that intervals 1 and 2 were within the first hour of testing, whereas interval 3 was in the second hour, and interval 4 in the third hour of testing.

Rajapaksha et al., 2015) but longer than that reported in other studies investigating latency to lie down after $4 \mathrm{~h}$ of lying deprivation (ranging from 4 to $7 \mathrm{~min}$ in Krebs et al., 2011, and Norring and Valros, 2016; 28 min in Tucker et al., 2018). We speculate that the differences in latency to lie down are due to methodological differences between the studies, such as feeding and milking times, and possible differences in ambient air temperature, which may have influenced cows' motivation to lie down.

There were no differences in feeding behavior or surface temperature between cows standing on different flooring types and for different durations. All cows had higher mean surface temperatures at the end of the 3-h standing duration compared with the first 30 min of standing, irrespective of flooring type. An increase in surface temperature with standing duration could indicate that motor units are recruited and this requires further investigation; however, we also cannot rule out a possible influence of ambient temperature on the temperature data loggers (iButtons) contributing to the observed increase.

Regardless of treatment, the overall results suggest that the $3 \mathrm{~h}$ of standing did not result in muscle fatigue (defined as in increase in MA and a decrease in MPF); however, the indication of muscular fatigue in animalbased studies has a general methodological problem: it is difficult to make animals do a measurable task that can be used as a reference value for fatigue evaluation. In the current study, this was attempted by forcing cows to shift weight to one hind leg and by comparing before and after values after standing. However, both the SEMG amplitude and the spectrum depend not only on the fatigue state, but also on the produced muscle force (Luttmann et al., 2000), which was not measured due to limitation of resources. In this case, an increase in the SEMG MA over time could be induced by an increase in the produced muscular force or by the development of muscular fatigue.

\section{CONCLUSIONS}

Rubber flooring resulted in a different initial behavioral response, including a higher stepping rate and more muscle shifts, compared with concrete in the first hour of standing. We propose that the difference in flooring is that cows are more willing to move on rubber than on concrete, at least early on. By the time 
cows stood for $3 \mathrm{~h}$, we detected a consistent increase in stepping rate on both surfaces and in some muscle activity parameters, perhaps because cows on all surfaces were moving more to cope with the effects of prolonged standing. The results regarding fatigue in relation to flooring type are inconclusive.

\section{ACKNOWLEDGMENTS}

This study was supported by USDA Multistate Research Project NC1029 (Washington, DC). K. Schütz's time and travel to University of California-Davis (UC Davis) was funded by AgResearch Ltd. (Hamilton, New Zealand). We gratefully acknowledge the support of the Department of Animal Science, College of Agricultural and Environmental Sciences, and the California Agricultural Experiment Station of UC Davis. We also thank UC Davis dairy farm manager Doug Gisi and the UC Davis undergraduate interns for their help throughout the experiments. We are also grateful to the UC Davis Veterinary orthopedic laboratory for sharing their equipment and software. Numat Ltd. (Oamaru, New Zealand) provided the rubber mats.

\section{REFERENCES}

Beggs, D. S., A. D. Fisher, E. C. Jongman, and P. H. Hemsworth. 2015. A survey of Australian dairy farmers to investigate animal welfare risks associated with increasing scale of production. J. Dairy Sci. 98:5330-5338. https://doi.org/10.3168/jds.2014-9239.

Bockstahler, B. B., R. Gesky, M. Mueller, J. G. Thalhammer, C. Peham, and I. Podbregar. 2009. Correlation of surface electromyography of the vastus lateralis muscle in dogs at a walk with joint kinematics and ground reaction forces. Vet. Surg. 38:754-761. https: //doi.org/10.1111/j.1532-950X.2009.00561.x.

Chapinal, N., A. M. de Passillé, J. Rushen, and C. B. Tucker. 2011. Short communication: Measures of weight distribution and frequency of steps as indicators of restless behavior. J. Dairy Sci. 94:800-803. https://doi.org/10.3168/jds.2010-3531.

Chapinal, N., and C. B. Tucker. 2012. Validation of an automated method to count steps while cows stand on a weighing platform and its application as a measure to detect lameness. J. Dairy Sci. 95:6523-6528. https://doi.org/10.3168/jds.2012-5742.

Colborne, G. R., D. M. Birtles, and I. C. Cacchione. 2001. Electromyographic and kinematic indicators of fatigue in horses: A pilot study. Equine Vet. J. Suppl. 33:89-93. https://doi.org/10.1111/j .2042-3306.2001.tb05367.x.

Cooper, M. D., D. R. Arney, and C. J. C. Phillips. 2007. Two- or fourhour lying deprivation on the behavior of lactating dairy cows. J. Dairy Sci. 90:1149-1158. https://doi.org/10.3168/jds.S0022 -0302(07)71601-6.

Flower, F. C., A. M. de Passillé, D. M. Weary, D. J. Sanderson, and J. Rushen. 2007. Softer, higher-friction flooring improves gait of cows with and without sole ulcers. J. Dairy Sci. 90:1235-1242. https:// doi.org/10.3168/jds.S0022-0302(07)71612-0.

Flower, F. C., and D. M. Weary. 2006. Effect of hoof pathologies on subjective assessments of dairy cow gait. J. Dairy Sci. 89:139-146. https://doi.org/10.3168/jds.S0022-0302(06)72077-X.

Freitas, S. M. S. F., S. A. Wieczorek, P. H. Marchetti, and M. Duarte. 2005. Age-related changes in human postural control of prolonged standing. Gait Posture 22:322-330. https://doi.org/10.1016/j .gaitpost.2004.11.001.
Hägg, G. M., A. Luttmann, and M. Jäger. 2000. Methodologies for evaluating electromyographic field data in ergonomics. J. Electromyogr. Kinesiol. 10:301-312. https://doi.org/10.1016/S1050 $-6411(00) 00022-5$.

Haufe, H. C., L. Gygax, B. Steiner, K. Friedli, M. Stauffacher, and B. Wechsler. 2009. Influence of floor type in the walking area of cubicle housing systems on the behaviour of dairy cows. Appl. Anim. Behav. Sci. 116:21-27. https://doi.org/10.1016/j.applanim 2008.07.004.

Hinterhofer, C., J. C. Ferguson, V. Apprich, H. Haider, and C. Stanek. 2005. A finite element model of the bovine claw under static load for evaluation of different flooring conditions. N. Z. Vet. J. 53:165170 .

Ito, K., D. M. Weary, and M. A. G. von Keyserlingk. 2009. Lying behavior: Assessing within- and between-herd variation in free-stallhoused dairy cows. J. Dairy Sci. 92:4412-4420. https://doi.org/10 $.3168 /$ jds.2009-2235.

Krebs, N., S. L. Berry, and C. B. Tucker. 2011. Restless behavior increases over time, but not with compressibility of the flooring surface, during forced standing at the feed bunk. J. Dairy Sci. 94:97-105. https://doi.org/10.3168/jds.2010-3089.

Ledgerwood, D. N., C. Winckler, and C. B. Tucker. 2010. Evaluation of data loggers, sampling intervals, and editing techniques for measuring the lying behavior of dairy cattle. J. Dairy Sci. 93:5129 5139. https://doi.org/10.3168/jds.2009-2945.

Licka, T., A. Frey, and C. Peham. 2009. Electromyographic activity of the longissimus dorsi muscles in horses when walking on a treadmill. Vet. J. 180:71-76. https://doi.org/10.1016/j.tvjl.2007.11.001.

Luttmann, A., M. Jäger, and W. Laurig. 2000. Electromyographical indication of muscular fatigue in occupational field studies. Int. J. Ind. Ergon. 25:645-660. https://doi.org/10.1016/S0169 -8141(99)00053-0.

Neveux, S., D. M. Weary, J. Rushen, M. A. G. von Keyserlingk, and A. M. de Passillé. 2006. Hoof discomfort changes how dairy cattle distribute their body weight. J. Dairy Sci. 89:2503-2509. https:// doi.org/10.3168/jds.S0022-0302(06)72325-6.

Norring, M., and A. Valros. 2016. The effect of lying motivation on cow behaviour. Appl. Anim. Behav. Sci. 176:1-5. https://doi.org/ 10.1016/j.applanim.2015.11.022.

Ottoni, E. B. 2000. EthoLog 2.2: A tool for the transcription and timing of behavior observation sessions. Behav. Res. Methods Instrum. Comput. 32:446-449. https://doi.org/10.3758/BF03200814.

Ouweltjes, W., M. Holzhauer, P. P. J. van der Tol, and J. van der Werf. 2009. Effects of two trimming methods of dairy cattle on concrete or rubber-covered slatted floors. J. Dairy Sci. 92:960-971. https://doi.org/10.3168/jds.2008-1559.

Pastell, M. E., and M. Kujala. 2007. A probabilistic neural network model for lameness detection. J. Dairy Sci. 90:2283-2292. https:// doi.org/10.3168/jds.2006-267.

Rajapaksha, E., and C. B. Tucker. 2014. How do cattle respond to sloped floors? An investigation using behavior and electromyograms. J. Dairy Sci. 97:2808-2815. https://doi.org/10.3168/jds .2013-7435.

Rajapaksha, E., and C. B. Tucker. 2015. Stepping behavior and muscle activity of dairy cows on uncomfortable standing surfaces presented under 1 or 4 legs. J. Dairy Sci. 98:295-304. https://doi.org/10 $.3168 /$ jds.2014-8652.

Rajapaksha, E., C. Winkler, and C. B. Tucker. 2015. Effect of rubber flooring on dairy cattle stepping behavior and muscle activity. J. Dairy Sci. 98:2462-2471. https://doi.org/10.3168/jds.2014-8930.

Robert, C., J. P. Valette, and J. M. Denoix. 2000. The effects of treadmill inclination and speed on the activity of two hindlimb muscles in the trotting horse. Equine Vet. J. 32:312-317. https://doi.org/ 10.2746/042516400777032246.

Schütz, K. E., and N. R. Cox. 2014. Effects of short-term repeated exposure to different flooring surfaces on the behavior and physiology of dairy cattle. J. Dairy Sci. 97:2753-2762. https://doi.org/10 .3168/jds.2013-7310.

Somers, J. G. C. J., K. Frankena, E. N. Noordhuizen-Stassen, and J. H. M. Metz. 2003. Prevalence of claw disorders in Dutch dairy 
cows exposed to several floor systems. J. Dairy Sci. 86:2082-2093. https://doi.org/10.3168/jds.S0022-0302(03)73797-7.

Telezhenko, E., and C. Bergsten. 2005. Influence of floor type on the locomotion of dairy cows. Appl. Anim. Behav. Sci. 93:183-197. https://doi.org/10.1016/j.applanim.2004.11.021.

Telezhenko, E., L. Lidfors, and C. Bergsten. 2007. Dairy cow preferences for soft or hard flooring when standing or walking. J. Dairy Sci. 90:3716-3724. https://doi.org/10.3168/jds.2006-876.

Tucker, C. B., L. M. Munksgaard, E. M. Mintline, and M. B. Jensen. 2018. Use of a pneumatic push gate to measure dairy cattle motivation to lie down in a deep-bedded area. Appl. Anim. Behav. Sci. 201:15-24. https://doi.org/10.1016/j.applanim.2017.018.

Tucker, C. B., D. M. Weary, A. M. de Passillé, B. Campbell, and J. Rushen. 2006. Flooring in front of the feed bunk affects feeding behavior and use of freestalls by dairy cows. J. Dairy Sci. 89:20652071. https://doi.org/10.3168/jds.S0022-0302(06)72274-3.

UBC Animal Welfare Program. 2013. SOP HOBO Data Loggers. University of British Columbia, Vancouver, BC, Canada.

van der Tol, P. P. J., J. H. M. Metz, E. N. Noordhuizen-Stassen, W. Back, C. R. Braam, and W. A. Weijs. 2005. Frictional forces required for unrestrained locomotion in dairy cattle. J. Dairy Sci. 88:615-624. https://doi.org/10.3168/jds.S0022-0302(05)72725-9.

Vanegas, J., M. Overton, S. L. Berry, and W. M. Sischo. 2006. Effect of rubber flooring on claw health in lactating dairy cows housed in free-stall barns. J. Dairy Sci. 89:4251-4258. https://doi.org/10 $.3168 /$ jds.S0022-0302(06)72471-7. 